\title{
FOUR CASES OF URINARY OBSTRUCTION
}

BY

\author{
A. V. NEALE, M.D., M.R.C.P. \\ (From the Children's Hospital, Birmingham.)
}

The frequency and importance of urinary tract defects, obstructions and infections in children is now well recognized, but unfortunately the recognition is often delayed until an emergency state of severe obstruction, uræmia or superadded infection brings the case under observation.

In a very interesting and comprehensive paper by Poynton and Sheldon ${ }^{1}$, the causes and effects of dilatation of the bladder and ureters in children are outlined and there is very little new information to be added to their observations. Therefore, the only reason for placing the following cases on record is in order to extend further the clinical illustrations of these particular disorders. Four cases will be outlined, in each of which a definite organic cause was found to be associated with dilatation of the bladder, ureters and renal pelves, all instances occurring in male children.

The cases here presented showed the cause of the disorder to be situated in the posterior part of the urethra, and in each instance a well recognized pathological state was demonstrable.

The following cases are presented:-

Case 1. Congenital urethral valves.

Case 2. Congenital urethral stricture.

Case 3. Sarcoma of the base of the bladder.

Case 4. Urethro-vesical calculus.

\section{Case reports.}

Case 1. Congenital urethral valves (with Figure 1).

Baby G., aged 9 days, male; third child in healthy family. At birth it was noticed that the recti muscles of the abdomen were widely separated, and later the umbilicus was observed to be weeping.

The baby was brought to hospital in a very poor physical condition, the mother stating that the child had passed very little urine since birth, and that there was unusual swelling of the abdomen. The bowel had acted normally, but feeding had been difficult. It was obvious on admission to the hospital, that the urinary bladder was very considerably distended and extremely tense. Careful abdominal palpation also revealed the outlines of distended thickened ureters and enlarged lobulated renal swellings.

A clinical diagnosis of congenital urethral valves was made. Very small quantities of urine escaped from the urethra, but the introduction of a small rubber catheter presented no difficulty and vesical drainage was established. There was no sepsis in the urinary tract and the urine was normal. The infant failed to survive.

Autopsy. At the necropsy an excellent example of urinary obstruction due 
to the presence of congenital mucosal valves in the posterior urethra was found, an arrangement whereby pressure by fluid in the vesical side caused closure of the posterior urethral canal. The drawing (Fig. 1) illustrates the extreme vesical hypertrophy and urethral dilatation. On the right side of the prostatic area a small acute abscess was present, this being apparently due to direct infection in the prostatic ducts, and being so placed as to cause quite complete occlusion, by lateral pressure, of the prostatic urethra.

There was no evidence of any other congenital physical defects in the child.

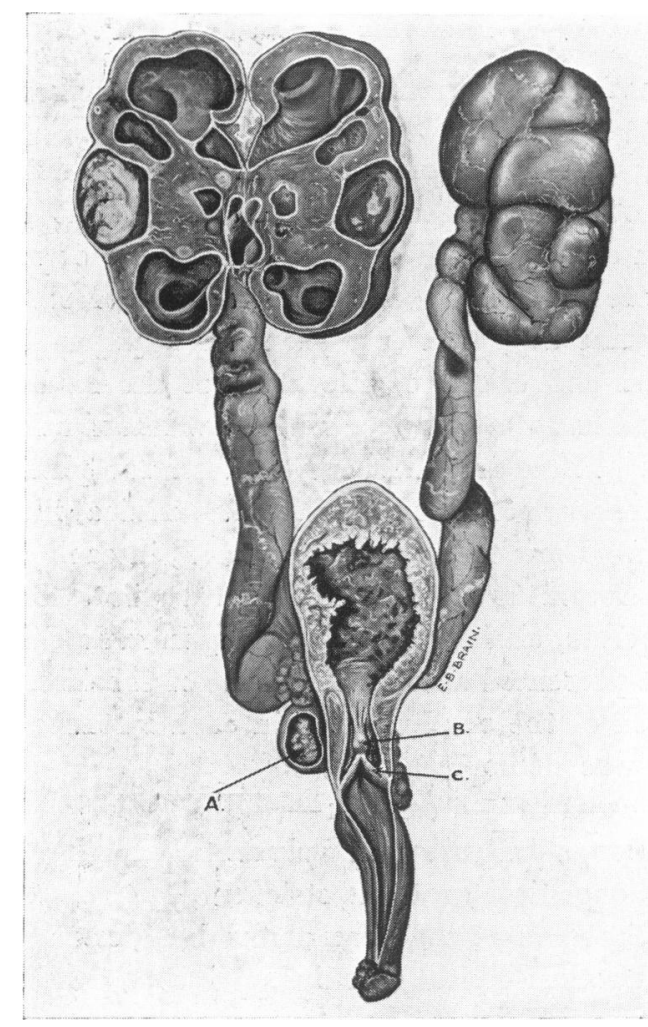

FIG. 1.-Case 1, Baby G., aged 9 days ; showing congenital urethral valves.
A. Perivesical abscess.
B. Prominent verumontanum.
C. Urethral valies.

Case 2. Congenital urethral stricture (with Figure 2).

R. C., aged $4 \frac{1}{4}$ years, male; first of four children, others healthy. The child was $10 \mathrm{lb}$. at birth and made good progress until pyuria was first discovered at about two years of age. This urinary infection never improved materially.

At the age of $4 \frac{1}{4}$ years this child was first seen at the Children's Hospital with a recent history of melæna. The general physical condition was moderate and there was no evidence of cardio-vascular disease, but the respiration was uræmic in type and the urine showed a heavy pyuria and infection with bacillus coli and streptococci. The bladder was observed to be somewhat dilated continuously, but urine was evacuated at intervals. The pyuria failed to respond to medicinal therapy and progressive uræmic phenomena, including vomiting and severe hæmorrhagic entero-colitis supervened. 
Autopsy. Necropsy revealed slight hypertrophy of the left ventricle without any evidence of intrinsic cardio-vascular disease. Each kidney was small and consisted of sacs containing thick purulent exudate. Both ureters were very distended, tortuous and thickened ( 1 in. diameter). The bladder was distended and somewhat thickened. The uretero-vesical orifices were dilated. The seat of urinary obstruction was found to be in the posterior urethra where, as shown in the

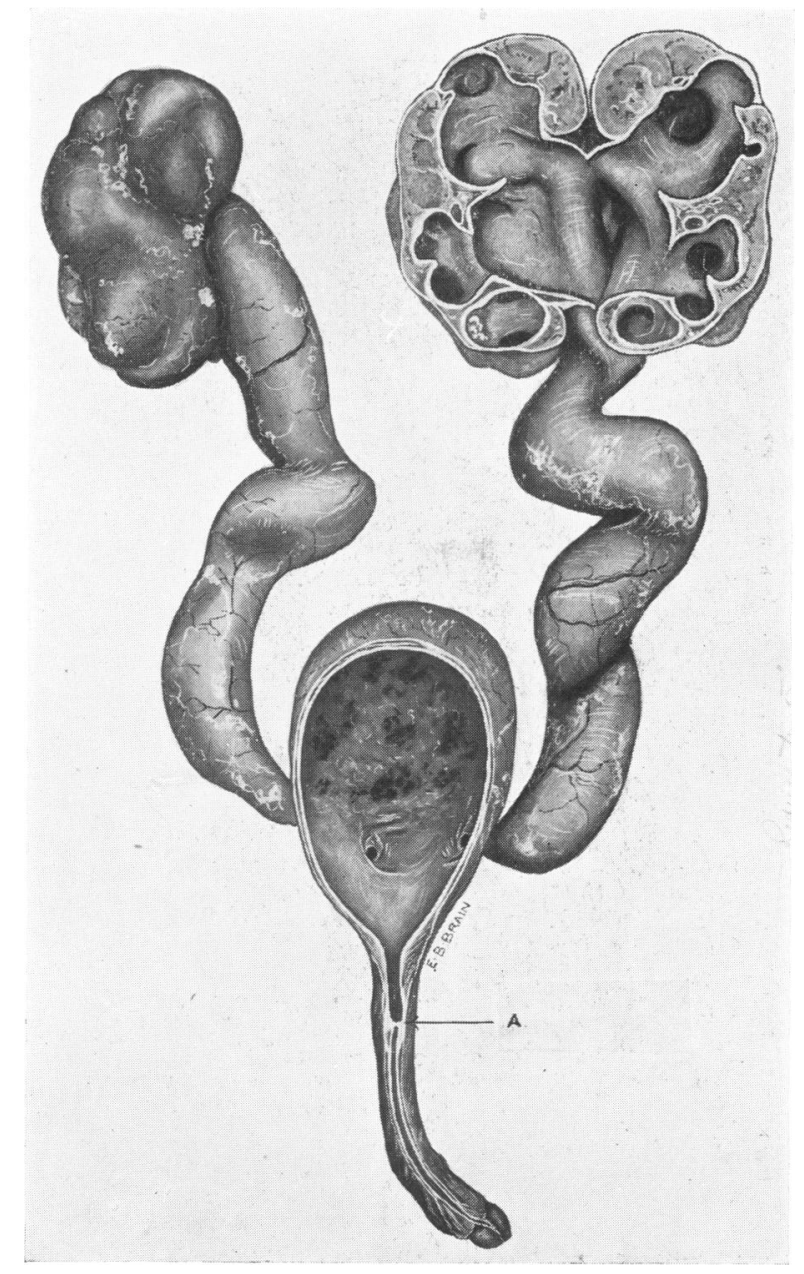

Fıci, 2.-Case 2, R. C., aged $4 \frac{1}{2}$ years, showing congenital urethral stricture.

A. Stricture.

drawing (Fig. 2), congenital narrowing of the urethral channel was present, and a small fold of thickened mucosa was also seen at this level. A narrow channel through the stricture could be determined, but apparently the associated renal tract infection had caused added mucosal swelling in the stricture area, thus rendering the urethral passage extremely narrow. The urethra distal to the stricture and the meatus urinarius were normal. 
Case 3. Sarcoma of base of bladder (with Figures 3, 4 and 5).

C. L., aged 1 year and 2 months, male; third of three children. Breast fed for nine months and made very good progress.

The first indication of urinary tract disease was occasional dysuria, and the detection of pyuria at the age of one year. The urinary tract infection failed to respond to medicinal therapy, and at 14 months of age the child was admitted to hospital with urinary retention; the bladder being very considerably distended and

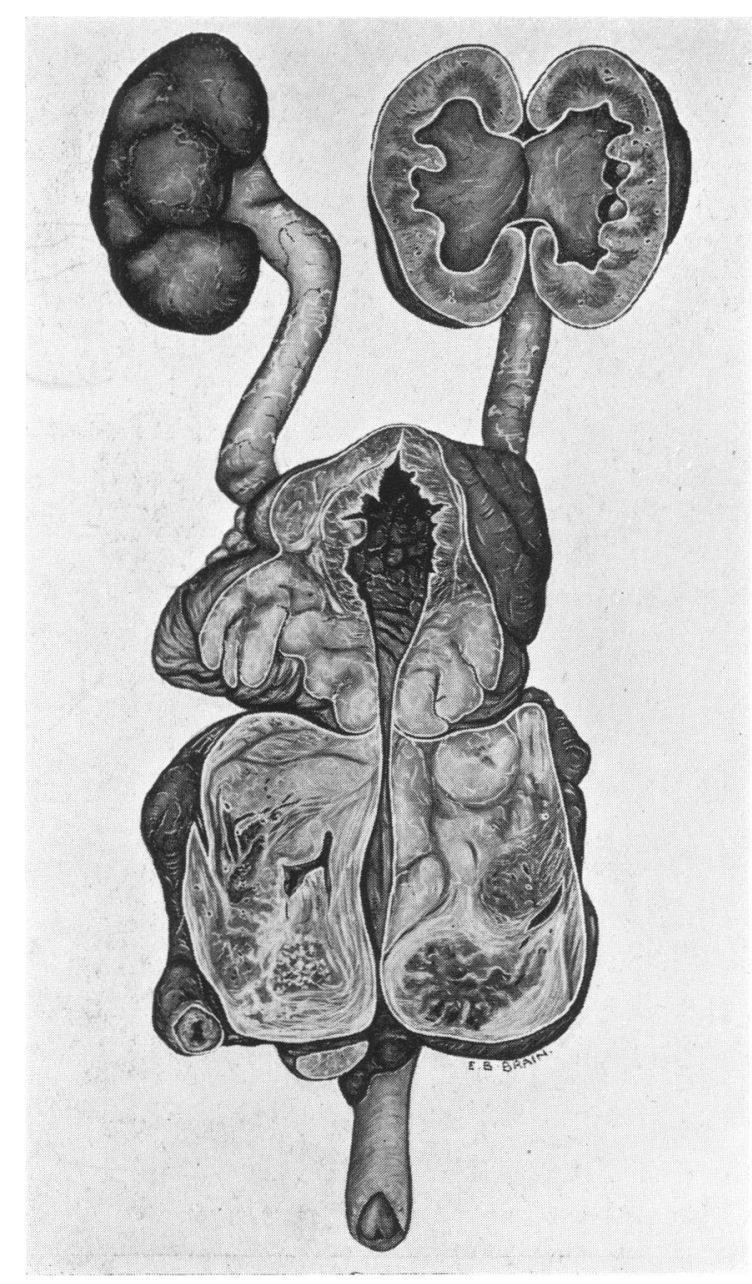

Fig. 3. - Case 3, showing sarcoma of the base of the bladder.

presenting as a hard suprapubic tumour. Rectal examination revealed a large mass disposed around the base of the bladder, the nature of which at this time was somewhat uncertain. My surgical colleague, Mr. Stammers, attempted to pass a small bougie along the urethra into the bladder without success, due to an obstruction near the posterior part of the urethra and neck of the bladder. Suprapubic cystotomy was performed and urinary tract drainage established, so producing a considerable temporary improvement in the child's general appearance. A few days later a smooth elastic mass was palpable in the perineum. Within ten days of this 
observation the perineal swelling had reached at least four times the size noticed before, had become hard and come to occupy practically the whole of the true pelvic cavity. There was no doubt that this was a rapidly proliferating neoplastic mass arising in the region of the prostatic gland.

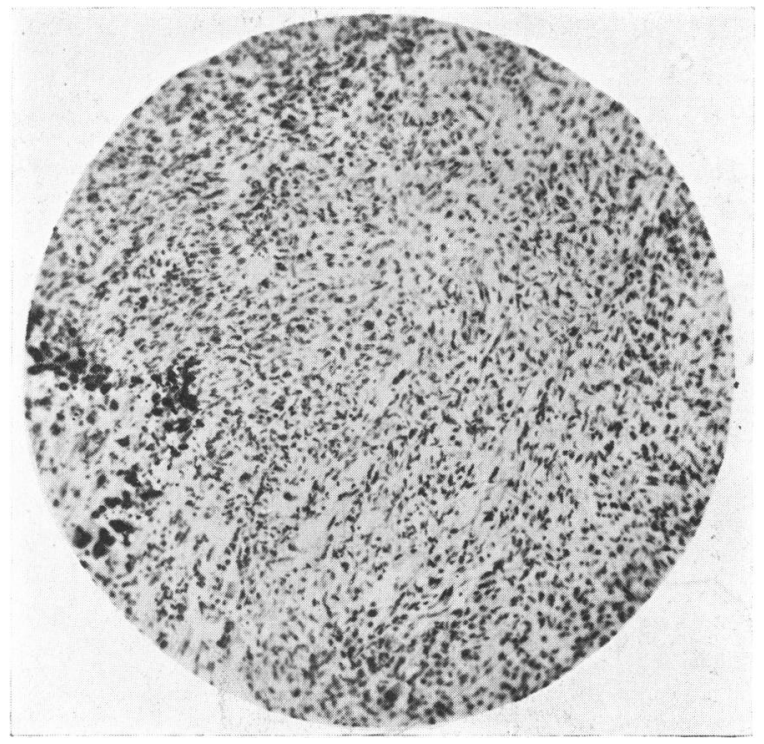

Fra. 4.-Case 3, showing sarcoma of the base of the bladder (low power).

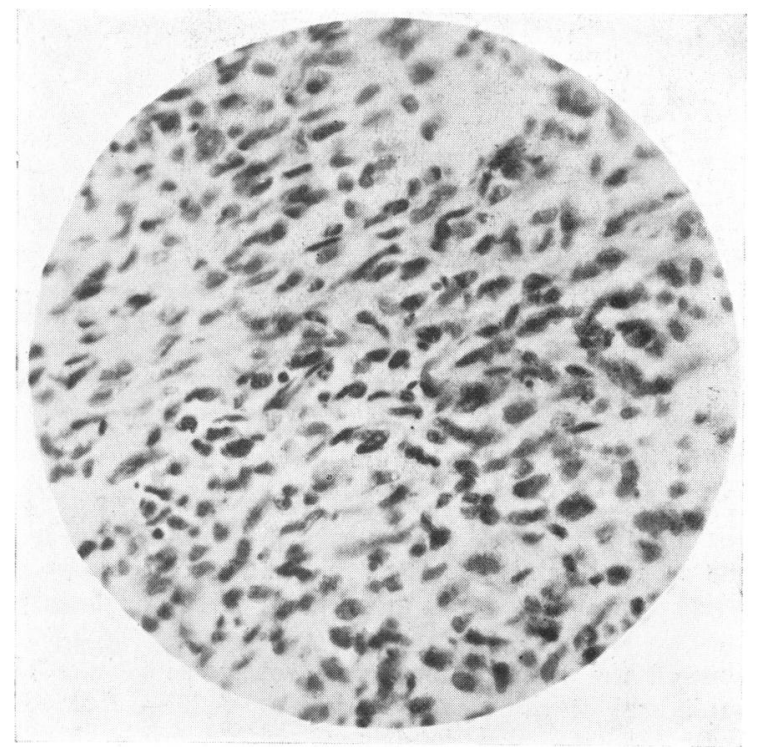

Fit. 5. - Case 3, showing sarcoma of the base of the bladder (high power).

Autopsy. At post-mortem examination the pelvic cavity was chiefly occupied by a soft neoplastic mass arising from the neck of the bladder and diffusely infiltrating 
the perineum and the ileo-psoas muscles. The wall of the bladder was grossly thickened and both ureters much dilated. The renal pelves were similarly distended with moderate compression, chiefly of the renal substance. Careful examination appeared to show that the neoplasm arose in the anterior part of the prostate gland, but owing to the diffuse nature of the infiltration certainty on this point was not possible. There were no metastases. The drawing (Fig. 3) illustrates the extent and site of the tumour and its relationship to the urinary tract obstruction.

Microscopical examination showed the neoplasm to be sarcomatous in type, and the microphotographs show the detailed histological structure (Figs. 4 and 5).

Case 4. Urethro-vesical calculus (with Figure 6).

J. B., aged 14 months, male. The child was apparently quite well until three

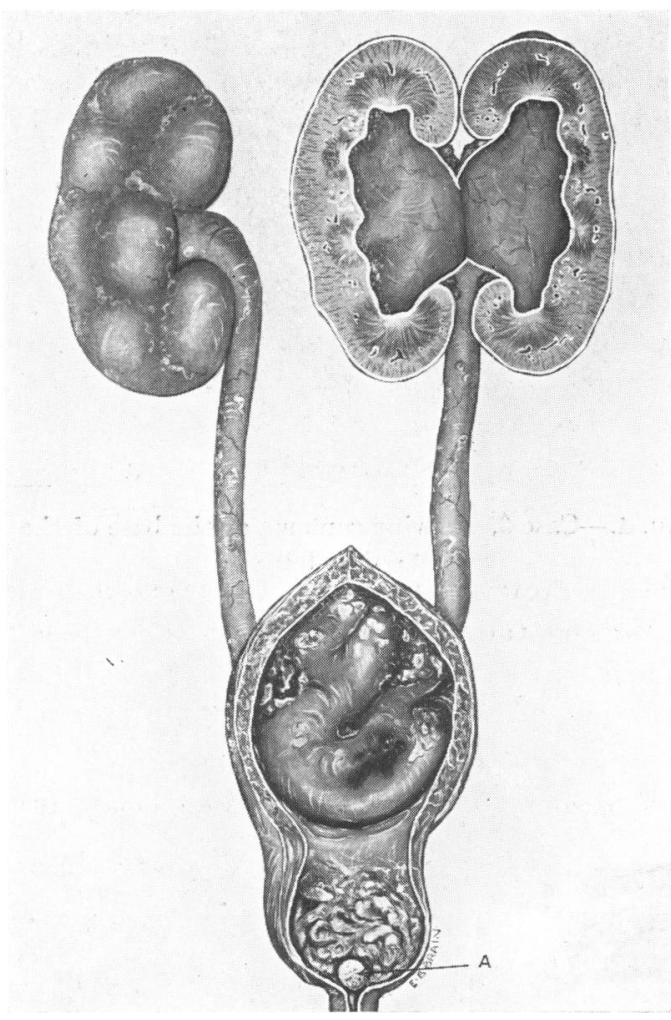

Fu: 6. -Case 4, showing urethro-vesicill calculus.

$$
\text { A. Calculus }
$$

weeks before admission to hospital. Some difficulty, however, in micturition had occurred from time to time, and circumcision had given no improvement. Severe straining at micturition, and only small amounts of urine had been passed just prior to admission.

Observation showed the child to be pale, drowsy, sometimes almost comatose, with contracted pupils and uræmic deep respiration. A large distended hard bladder was present. A soft catheter was introduced with considerable difficulty and a small amount of thick purulent urine escaped. Suprapubic cystotomy was performed under local anæsthetic (Mr. Stammers), and masses of membraneous necrotic material found and removed from the neck of the bladder. No calculus was detected at this time. Broncho-pneumonia supervened. 
Autopsy. Each kidney was enlarged and showed diffuse pyelonephritis, with dilatation of the ureters. Dissection revealed at the neck of the bladder and posterior urethra, a soft mass of collagenous material consisting of necrotic mucosa and fibrin, in the centre of which was an irregular white calculus the size of a small bean, so placed as to cause almost complete urethral obstruction. The drawing shows the existent condition (Fig. 6).

\section{Comments.}

The four cases here recorded and illustrated afford good examples of the particular disorders found.

In the case of congenital urethral valves (Case 1), it is unusual for urinary obstruction to occur in an infant so young as in the instance here noted. In this patient the urethral mucosal folds were unusually well marked and the valvular effect was considerable. In cases which are detected before gross urinary obstruction and sepsis have occurred satisfactory treatment has been evolved, but unfortunately such added difficulties are frequently present when the patient comes under observation.

Congenital urethral stricture (Case 2) is apparently an extremely unusual cause of urinary obstruction in young children, although strictural narrowing of a ureter is among the commoner forms of congenital abnormality in the urinary tract.

Chronic urinary sepsis as a sign of disease in the renal tract requiring careful and extended investigation is again indicated.

I am indebted to Professor Parsons, Dr. Smellie and Dr. Gittins for co-operation in obtaining the clinical and pathological notes, and to $\mathrm{Mr}$. Brain for the drawings.

\section{REFERENGE.}

1. Poynton, F. J., \& Sheldon, W., Arch. Dis. Childh., Lond., 1927, II, 251. 